\title{
Desempenho de poedeiras comerciais submetidas ou não a diferentes métodos de debicagem
}

\author{
Performance of layer hens submitted or not to different methods of the beak trimming
}

\author{
Lúcio Francelino Araújo ${ }^{1}$ Marcos Barcelos Cafée ${ }^{2}$ Nadja Susana Mogyca Leandro ${ }^{2}$ \\ Otto Mack Junqueira ${ }^{3}$ Cristiane Soares da Silva Araújo ${ }^{3}$ \\ Maria Inês Rodrigues da Cunha ${ }^{4}$ Claudia Cassimira da Silva ${ }^{5}$
}

RESUMO

Foram utilizadas 288 aves da linhagem Isa Babcock avaliando o efeito da debicagem leve, severa e da não debicagem sobre o desempenho de poedeiras, distribuídas em delineamento inteiramente casualizado em esquema fatorial $3 \times 3$ (primeira debicagem $x$ segunda debicagem), com quatro repetições de oito aves cada. A primeira debicagem foi realizada aos nove dias e a segunda debicagem às 12 semanas. Avaliou-se consumo de ração, peso das aves, percentagem de postura e conversão alimentar em quatro períodos de 28 dias cada. De acordo com os resultados, aves com debicagem severa apresentaram menor consumo de ração e menor percentagem de postura $(P<0,05)$.

Palavras-chave: debicagem, desempenho, poedeiras.

\section{ABSTRACT}

One experiment was conducted using 288 Isa Babcock laying hens, to study the effects of beak trimming (not trimming, light and severe). The hens were distributed in an at random experimental design, in factorial arrangement $3 \times 3$ ( first $x$ second beak trimming ). The first one was done at nine days of age and the second at twelve weeks of age. Feed intake, body weight, egg production and feed conversion in four periods of twenty eight days each was evaluated. According to the results, the birds at severe beak trimming showed less feed intake and worst egg production $(P<0.05)$.

Key words: beak trimming, performance, layer hens.

\section{INTRODUÇÃO}

Até 1920 as criações de poedeiras eram pequenas e sem grande aprimoramento das técnicas de manejo. Com o desenvolvimento da incubação artificial, do conhecimento das necessidades nutricionais e de controle de doenças, foi possível o aumento das criações. Porém, todas estas melhorias geraram problemas comportamentais como resultado do aumento de tamanho e de densidade das criações (CRAIG \& SWANSON, 1994).

A formação de hierarquia entre as aves pode influenciar os índices de produtividade, fato agravante na criação de poedeiras, já que possuem maior tempo de vida produtiva (EGLADSON, 1993). A pressão social pode gerar competição por espaço, podendo resultar em comportamentos de agressão e submissão que acabam por definir a ordem hierárquica, provocando estresse e consequentemente desuniformidade do lote, de acordo com Fisher (1975), citado por ODA et al. (2000).

Atualmente, a criação de poedeiras comerciais é feita quase que exclusivamente em gaiolas, havendo a necessidade da debicagem em

\footnotetext{
${ }^{1}$ Faculdade de Zootecnia e Engenharia de Alimentos (FZEA), Universidade de São Paulo (USP), Departamento de Zootecnia, Av. Duque de Caxias Norte, 225, 13635-900, Pirassununga, SP. E-mail: lfaraujo@usp.br. Autor para correspondência.

${ }^{2}$ Escola de Veterinária, Universidade Federal de Goiás (UFG).

${ }^{3}$ Faculdade de Ciências Agrárias e Veterinárias (FCAVJ), Universidade Estadual Paulista (UNESP) Jaboticabal, SP.

${ }^{4}$ Médico Veterinário.

${ }^{5}$ Aluno de Graduação, FZEA, USP.
} 
função da pressão social (BELL \& KUNEY, 1991). Porém, tanto em sistemas de piso como o de gaiolas, as poedeiras podem adquirir o vício do canibalismo (HUNTON, 1998a). De acordo com CRAIG \& LEE (1990), houve maior incidência de problemas com canibalismo e bicagem de penas na ausência da debicagem, tanto em criações no sistema de piso quanto em sistemas de gaiolas.

A debicagem que é uma prática de manejo que tem sido grandemente utilizada pela indústria avícola com o objetivo de reduzir o canibalismo, mortalidade e a queda do desempenho produtivo das aves, proporciona ainda melhor aproveitamento da ração. A ocorrência de bicagem de penas e de canibalismo, segundo KEELING (1995), são influenciados por fatores hormonais. A perda de penas resultante da agressão de outra ave pode causar tanto problemas econômicos ao produtor como problemas de bem estar às aves. A perda econômica dá-se pelo fato de que a retirada de penas leva a problemas de mantença da temperatura corporal, levando a um aumento no consumo alimentar (LEESON \& MORRISON, 1978), podendo ser superior a $27 \%$ (TAUSON \& SVENSSON, 1980). Outra perda econômica resultante do canibalismo se refere ao aumento na incidência de ovos bicados.

Um dos maiores desafios para os criadores de poedeiras é alcançar um nível de debicagem adequado (HUNTON, 1998b). Por isto, a debicagem é considerada uma operação de precisão onde a experiência da equipe que a realiza é uma característica primordial para seu sucesso. É realizada com uma lâmina quente e consiste na retirada de parte superior e inferior do bico. Neste caso, a produção da poedeira pode manter-se constante, superior ou inferior, se esta prática não for devidamente empregada. Segundo CRAIG (1992), o estresse, resultante do mau procedimento e de falhas na debicagem, pode afetar a produção inicial de ovos. A debicagem tem sido uma prática de manejo muito discutida quando se refere à bem estar dos animais, pois, apesar de seus efeitos benéficos, há evidências de que pode causar dor à ave (CRAIG \& LEE, 1990; GENTLE et al.,1990; LEE \& CRAIG,1990), mas STRUWE et al. (1992), em seu trabalho, descobriu que aves debicadas sofrem menor estresse quando comparadas com aves que não foram debicadas e sofrem com a agressividade de suas companheiras.

De acordo com CARREY \& LASSITER (1995), a indústria avícola tem empregado vários procedimentos em relação à idade e métodos ideais para a debicagem, sendo a primeira debicagem realizada entre 7 e 10 dias de idade da ave, havendo vários trabalhos que procuram demonstrar a melhor idade à segunda debicagem (CARREY, 1990). O objetivo deste trabalho foi avaliar o efeito de diferentes debicagens em poedeiras comerciais sobre seu desempenho produtivo.

\section{MATERIAL E MÉTODOS}

Foram utilizadas 288 frangas da linhagem comercial Isa Babcock, distribuídas em delineamento inteiramente casualizado, em esquema fatorial 3x3 (primeira debicagem $\mathrm{X}$ segunda debicagem), com nove tratamentos e quatro repetições de 24 aves cada, sendo que os tratamentos foram uma combinação entre os níveis das duas debicagens realizadas. No nono dia de idade, as aves foram debicadas de duas diferentes formas originando três grupos: aves não debicadas (ND), submetidas à debicagem leve (DL) e à debicagem severa (DS) sendo a debicagem leve realizada à $3 \mathrm{~mm}$ da narina e a debicagem severa à $2 \mathrm{~mm}$ da narina.

A segunda debicagem foi realizada as 12 semanas de idade das aves sendo que a DL foi feita à $7 \mathrm{~mm}$ da narina das aves, e a DS à $5 \mathrm{~mm}$ da narina (considerando a base da narina como referência), medindo-se com o auxílio de um paquímetro e delimitados com caneta porosa para facilitar e padronizar a debicagem alcançando o tamanho desejado. A temperatura da lâmina do debicador foi mantida em torno de $700^{\circ} \mathrm{C}$.

A dieta fornecida às aves, durante o período experimental, foi formulada à base de milho e farelo de soja e os seus níveis nutricionais são apresentados na tabela 1. Todas as aves tinham à disposição, de igual forma, água através de bebedouros nipples e ração a qual era fornecida duas vezes ao dia. O programa de luz utilizado foi o de luz natural. As aves foram transferidas para as gaiolas duas semanas antes do início do experimento para um período de adaptação. As variáveis estudadas foram o peso corporal (g), consumo de ração (g), conversão alimentar $\left(\mathrm{kg} \mathrm{dz}^{-1}\right)$ e taxa de produção de ovos (\%), em 4 períodos de 28 dias cada, sendo a avaliação destas características iniciadas na 18a semana de idade.

Em caso de significância estatística, as médias dos tratamentos foram comparadas através do teste de Tukey $(\mathrm{P}<0,05)$, sendo adotado o seguinte modelo estatístico: $Y_{\mathrm{ij}}=\mathrm{m}+\mathrm{P}_{\mathrm{i}}+\mathrm{D}_{\mathrm{j}}+(\mathrm{PD})_{\mathrm{ij}}+\mathrm{e}_{\mathrm{ij}}$, onde: $\mathrm{Y}_{\mathrm{ij}}=$ valor da parcela com a primeira debicagem i e a segunda debicagem $\mathrm{j} ; \mathrm{m}=$ média geral; $\mathrm{P}_{\mathrm{i}}=$ Efeito da primeira debicagem $\mathrm{i}(\mathrm{i}=1,2, \mathrm{e}) ; \mathrm{D}_{\mathrm{j}}=$ Efeito da segunda debicagem j $(\mathrm{j}=1,2,3)$; $(P D)_{i j}=$ efeito da interação entre a primeira debicagem $\mathrm{i}$ e a segunda debicagem $\mathrm{j}$; $\mathrm{e}_{\mathrm{ij}}=$ erro aleatório associado com cada observação $\mathrm{Y}_{\mathrm{ij}}$. 
Tabela 1 - Formulação e níveis nutricionais da dieta utilizada durante o período experimental (18 a 34 semanas de idade)

\begin{tabular}{lc}
\hline \multicolumn{1}{c}{ Ingrediente } & $(\%)$ \\
\hline Milho & 58,15 \\
Farelo de soja & 28,00 \\
Óleo de soja & 3,60 \\
Calcário & 7,87 \\
Fosfato bicálcico & 1,58 \\
Sal comum & 0,30 \\
Suplemento vitamínico/mineral* & 0,50 \\
Total & 100,00 \\
\hline & \\
\hline EM, kcal/kg & Análise calculada \\
PB (\%) & 2.940 \\
Ca (\%) & 17,90 \\
Pt (\%) & 3,50 \\
Pd (\%) & 0,70 \\
Lisina (\%) & 0,48 \\
Metionina (\%) & 0,95 \\
Met+Cis (\%) & 0,28 \\
Na (\%) & 0,59 \\
&
\end{tabular}

* Composição por kg: vit A, 800.000UI; vit D, 100.000UI; vit E, $1.000 \mathrm{mg}$; vit $\mathrm{K}, 100 \mathrm{mg}$; vit $\mathrm{B}_{2}, 400 \mathrm{mg}$; vit $\mathrm{B}_{12}, 2.000 \mathrm{mcg}$; pantotenato de cálcio, 440mg; niacina, 2.000mg; colina, 50.000mg; I, 60mg; Se, 20mg; Mn, 6.000mg; Zn, 10.000mg; Cu, $15.000 \mathrm{mg}$; Fé, $10.000 \mathrm{mg}$, promotor de crescimento, $10.000 \mathrm{mg}$; antioxidante, 125mg; excipiente q.s.p., $1.000 \mathrm{~g}$.

\section{RESULTADOS E DISCUSSÃO}

Embora não tendo sido apresentados os dados referentes aos quatro períodos avaliados de forma distinta, vale ressaltar que, para todas as características estudadas, as aves que foram debicadas de forma severa apresentaram os piores resultados nos primeiros períodos ocorrendo sua recuperação no final do experimento, igualando-se aos demais tratamentos.

A tabela 2 apresenta os resultados durante todo o período experimental. Não houve interação entre os fatores estudados e, como pôde ser observado, não ocorreu influência da primeira debicagem sobre o peso médio, a conversão alimentar e a taxa de produção de ovos havendo, contudo, menor consumo de ração para as aves que tiveram debicagem severa $(\mathrm{P}<0,05)$. Embora não ocorrendo diferença estatística, aves que foram debicadas severamente, apresentaram menor peso e menor conversão alimentar. Sob os efeitos da segunda debicagem, houve uma diminuição no consumo de ração, sendo que as aves com debicagem severa apresentaram menor consumo, seguido de aves com debicagem leve $(\mathrm{P}<0,05)$. As aves com debicagem leve apresentaram uma melhor produção de ovos e conseqüentemente, uma melhor conversão alimentar.
Embora aves com debicagem severa apresentassem menor consumo de ração, as mesmas tiveram menor taxa de postura e, numericamente, pior conversão alimentar.

Os dados demonstrados na literatura confirmam os achados do presente estudo no que se refere \á redução do consumo de ração em aves que sofreram debicagem severa. Desta maneira, ANDRADE \& CARSON (1975) observaram uma dramática e imediata redução no consumo de ração de aves que foram debicadas, sendo que, no início de postura, as mesmas apresentaram menor consumo de ração. Ainda, LEE \& CRAIG (1990), LEE (1980) e VAN NIEKERK et al. (1999), também relataram menor consumo de ração de aves debicadas, ocorrendo, porém melhor conversão alimentar, diferindo dos resultados encontrados neste experimento. Em estudo de DEATON et al. (1988), os autores encontraram uma severa redução no consumo de ração de aves debicadas, recebendo ração peletizadas, quando comparadas com aves debicadas que recebiam dietas fareladas.

A debicagem tem sido relatada como responsável pela melhoria da conversão alimentar (LEE, 1980; LEE \& REID, 1977), durante o período de postura. Isto se deve ao fato de que as aves não debicadas apresentam maior desperdício de ração, quando comparadas com as aves debicadas. Quando confrontamos esta afirmação com os resultados deste experimento, foi possível observar que a melhoria na conversão alimentar somente ocorreu com as aves que sofreram uma debicagem leve; a debicagem severa proporcionou pior efeito para esta característica de produção.

Diferentes resultados têm sido encontrados para peso corporal de aves debicadas. Os dados de peso corporal do presente estudo concordam com os achados de BRAY et al. (1960) os quais relataram não haver efeitos significantes no peso corporal de aves, após terem sido debicadas. Resultados semelhantes foram encontrados por SANDILANDS \& SAVORY (2002), os quais observaram que não há diferença entre o peso corporal de aves debicadas e não debicadas, porém os autores relacionam este resultado com o fato de quem em seu trabalhom houve a retirada de apenas um quarto do bico, o que seria pouco frente a outros trabalhos que retiram um terço ou até mesmo um meio do bico. Porém, a maioria dos trabalhos publicados como LEE \& CRAIG (1990) e CARREY \& LASSITER (1995), evidenciaram uma redução no peso corporal das aves debicadas no período imediatamente posterior à realização desta prática de manejo, ocorrendo recuperação destas aves nos períodos 
Tabela 2 - Consumo de ração, peso médio, conversão alimentar e taxa de produção de ovos no período experimental total.

\begin{tabular}{|c|c|c|c|c|}
\hline & \multicolumn{4}{|c|}{$1^{\underline{a}}$ Debicagem } \\
\hline & Não debicada & Debicagem leve & Debicagem severa & $\mathrm{CV}(\%)$ \\
\hline Consumo (g) & $11.168 \mathrm{~A}$ & $11.135 \mathrm{~A}$ & $10.679 \mathrm{~B}$ & 3.87 \\
\hline Peso (g) & 1.399 & 1.386 & 1.385 & 4.59 \\
\hline Conversão(kg g ${ }^{-1}$ ) & 1.56 & 1.59 & 1.48 & 8.97 \\
\hline \multirow[t]{2}{*}{ Produção (\%) } & 77.78 & 77.38 & 78.25 & 7.32 \\
\hline & \multicolumn{4}{|c|}{$2^{\underline{a}}$ Debicagem } \\
\hline Consumo (g) & $11.284 \mathrm{~A}$ & $11.035 \mathrm{AB}$ & $10.663 \mathrm{~B}$ & 3.87 \\
\hline Peso (g) & 1.411 & 1.389 & 1.369 & 4.59 \\
\hline Conversão(kg g $\left.{ }^{-1}\right)$ & 1.57 & 1.46 & 1.60 & 8.97 \\
\hline Produção (\%) & 79.20 & 81.50 & 72.72 & 7.32 \\
\hline
\end{tabular}

Médias seguidas de letras iguais não diferem estatisticamente pelo Teste de Tukey a 5\%.

seguintes. Por outro lado, CAMP et al. (1955) afirmaram ocorrer aumento no peso corporal das aves após as mesmas terem sido debicadas.

Os efeitos da debicagem sobre a produção de ovos tem sido investigado por vários pesquisadores sendo encontrados resultados divergentes. Segundo ANDRADE \& CARSON (1975) e LEE (1980) não houve diferenças estatísticas para produção de ovos em aves que foram debicadas quando comparadas com o grupo controle. Esses dados concordam com os resultados do presente experimento já que as aves que foram debicadas severamente tiveram a mesma produção de ovos daquelas não debicadas. Entretanto não há concordância com os achados de SAKOMURA et al. (1997) que observaram menor produção de ovos nas aves debicadas quando comparadas às não debicadas, fato confirmado por VAN NIEKERK et al. (1999). De acordo com BEANE et al. (1967), a debicagem retarda a maturidade sexual das poedeiras podendo assim, as aves que sofreram tal procedimento, apresentarem menor produção de ovos no início do ciclo produtivo. Em experimento de SAKOMURA et al. (1997), observou - se atraso de 4 a 5 dias na maturidade sexual das aves debicadas comparada às não debicadas, sendo, portanto, estas últimas mais precoces. Resultados semelhantes foram encontrados por LEE \& REID (1975) e ANDRADE \& CARSON (1975). A propensão à bicagem de penas e canibalismo, segundo resultados de KEELING (1995), estaria relacionada a fatores hormonais no início da postura. No trabalho de HUGHES (1973), o uso de implantes de estrógeno e progesterona mostrou que as aves sexualmente maduras apresentaram maior incidência de bicagem de penas. Além disso, observou-se, no presente estudo, que a debicagem leve foi a que proporcionou maior produção de ovos para as aves provavelmente pelo procedimento ter sido menos drástico. Segundo CUNNINGHAM (1992), a produção de ovos em poedeiras comerciais está relacionada, provavelmente, à qualidade do processo de debicagem ao qual a ave foi submetida.

\section{CONCLUSÕES}

Nas condições experimentais empregadas, a debicagem realizada de forma severa, no período de recria de frangas, afetou negativamente a produção de ovos e aumentou o consumo de ração de poedeiras comerciais. Por outro lado, a debicagem leve permitiu melhores parâmetros de produção na fase de postura.

\section{REFERÊNCIAS BIBLIOGRÁFICAS}

ANDRADE, A.N.; CARSON, J.R. The effect of age at and methods of debeaking on future performance of White Leghorn Pullets. Poultry Science, v.54, p.666-674, 1975.

BEANE, W.L. et al. Size of debeak guide and cauterization time on the performance of Leghorn chickens. Poultry Science, v.46, p.1232, 1967.

BELL, D.D.; KUNEY, D.R. Effect of beak-trimming age and high fiber grower diets on layer performance. Poultry Science, v.70, p.1105-1112, 1991.

BRAY, D.J. et al. Performance of pullets debeaked at various times during the laying year. Poultry Science, v.39, p.15461550, 1960 .

Ciência Rural, v.35, n.1, jan-fev, 2005. 
CAMP, A.A. et al. Debeaking in commercial broiler production. Poultry Science, v.34, p.371-375, 1955.

CARREY, J.B. Influence of age at final beak trimming on pullet and layer performance. Poultry Science, v.69, p.14611466, 1990.

CARREY, J.B.; LASSITER, B.W. Influences of age at final beak trim on the productive performance of commercial layers. Poultry Science, v.74, p.615-619, 1995.

CRAIG, J.V.; LEE, H.Y. Beak trimming and genetic stock effects on behavior and mortality from cannibalism in White Leghorn-type pullets. Applied Animal Behavior Science, v.25, p.107-123, 1990

CRAIG, J.V. Beak trimming benefits vary among egg-straim pullets of different genetic stoks. Poultry Science, v.12, n.71, p.2007-2013, 1992

CRAIG, J.V.; SWANSON, J.C. Rewiew: Welfare perspectives on hens kept for egg production. Poultry Science, v.73, p.921-938, 1994.

CUNNINGHAM, D.L. Beak trimming effects on performance, behavior and welfare of chickens: a review. Journal Applied Poultry Research, v.1, p.129-134, 1992

DEATON, J.W. et al. Effect of beak trimming on body weight and feed intake of broiler roaster fed pellets or mash. Poultry Science, v.67, p.1514-1517, 1988.

EGLADSON, J.C. Comportamento e fertilidade. Revista Avicultura Ciência e Tecnologia - FACTA, n.10, p.16-18, 1993

GENTLE, M.J. et al. Behavior evidence for persistent pain following partial beak amputation in chickens. Applied Animal Behavior Science, v.27, p.149-157, 1990.

HUGHES, B.O. The effect of implanted gonadal hormones on feather pecking and cannibalism in pullets. British Poultry Science, v.14, p.341-348, 1973.

HUNTON, P. The beak trimming controversy. World Poultry, v.14, n.2, p.42-43, 1998a.

HUNTON, P. La polla perfecta. Avicultura Professional, v.16, p.25-27, 1998b.

KEELING, L.J. Feather pecking and cannibalism in layers.
Poultry International, v.34, p.46-50, 1995.

LEE, H.Y.; CRAIG, J.V. Beak trimming effects on the behavior and weight gain of floor-reared, egg-strain pullets from three genetic stocks during the rearing period. Poultry Science, v.69, p.568-575, 1990

LEE, K.; REID, L.S. The effects of day - old debeaking and for Marek's desease vaccination on the laying performance of pullets. Poultry Science, v.54, p.1785, 1975 .

LEE, K.; REID, L.S. The effects of Marek's disease vaccination na day-old debeaking on the performance of growing pullets and laying hens. Poultry Science, v.56, p.736-740, 1977.

LEE, K. Long term effects of Marek's disease vaccination with cell-free Herpesvirus of turkey and age at debeaking on performance and mortality of White Leghorns. Poultry Science, v.59, p.2002-2007, 1980.

LEESON, S.; MORRISON, W.D. Effect of feather cover on feed efficiency in laying birds. Poultry Science, v.57, p.1094-1096, 1978.

ODA, P.K. et al. Desempenho comparativo entre duas linhagens de poedeiras comerciais debicadas em diferentes idades na fase de recria. Ciência Rural, v.30, n.4, p.693698, 2000 .

SAKOMURA, N.K. et al. Efeito da debicagem e do enriquecimento ambiental no desempenho de galinhas poedeiras. ARS Veterinária, v.13, p.59-67, 1997.

SANDILANDS, V.; SAVORY, C.J. Ontogeny of behavior in intact and beak trimmed layer pullets, with special reference to preening. British Poultry Science, v.43, p.182-189, 2002.

STRUWE, F.J. et al. Stress measurements on beak-trimmed and untrimmed pullets. Poultry Science, v.71, p.1154-1162, $1992 \mathrm{a}$

TAUSON, R.; SVENSSON, S.A. Influence of plumage condition on the hen's feed requirement. Swedish Journal Agricultural Research, v.10, p.35-39, 1980.

VAN NIEKERK, G.C.M. et al. Advantages and disadvantages of beak trimming of laying hens. World Poultry, v.15, n.11, p.25-28, 1999 